\title{
As Forças do Figural ou Algumas Categorias de Análise para Dramaturgias Modernas e Contemporâneas
}

\author{
Nayara Macedo Barbosa de Brito \\ Universidade Federal da Bahia - UFBA, Salvador/BA, Brasil \\ E-mail: nay_brito13@hotmail.com
}

\section{Resumo}

A personagem dramática, conforme forjada pela tradição aristotélico-hegeliana, enfrentou um processo de decomposição e posterior recomposição, sob novas bases e nomenclaturas, ao longo do século XX. Nesse sentido, propomo-nos a investigar a pertinência da concepção de figura desenvolvida por Gilles Deleuze (1981) a partir da análise da obra do pintor anglo-irlandês Francis Bacon e enquanto desenvolvimento teórico da noção homônima elaborada por Jean-François Lyotard (1979) para a análise de um recorte das dramaturgias moderna e contemporânea. Para tanto, realizamos o cotejamento de alguns exemplos dessas dramaturgias e suas concretizações cênicas com as pinturas baconeanas, organizando nossa discussão a partir de algumas categorias analíticas levantadas por Deleuze em seu estudo.

\section{Palavras-chave}

Figura. Figural. Dramaturgia Moderna.

Dramaturgia Contemporânea. Francis Bacon.
The dramatic character, as forged by the Aristotelian-Hegelian tradition, got through a decomposition-recomposition process throughout the 20th century, achieving new basis and nomenclature. For that matter, we propose to investigate the pertinence of the Figure's conception developed by Gilles Deleuze (1981) from the analysis of the Anglo-Irish painter Francis Bacon's work and as a theoretical development of the homonymous notion formulated by Jean-François Lyotard (1979) to the analysis of a part of the modern and contemporary dramaturgies. To do so, we collate a few examples of this dramaturgy and its staging with the Baconean paintings, organizing our discussion from some of the analytical categories raised by Deleuze in his study.

Keywords

Figure. Figural. Modern Dramaturgy.

Contemporary Dramaturgy. Francis Bacon. 
É pelo menos desde A Gaivota (1895), de Anton Tchekhov, que a queixa em relação à ausência de "personagens vivas" e à raridade de ações efetivamente dramáticas pulula nas discussões sobre Teatro. A modernidade estética da qual a tensão $\mathrm{Na}$ turalismo-Simbolismo (presente na peça tchekhoviana) é representativa se caracterizou, entre outros aspectos relacionados ao objeto da referida queixa, por uma emancipação da cena em relação a um ideal mimético (cf. RYNGAERT; SERMON, 2006, p. 110), entendido como o da identificação absoluta entre o real e o representado, ideal esse que, por sua vez, refletiu outro, o de unidade da personagem, buscado e sempre frustrado ao longo da história, como defende a professora Maria Lúcia Levy Candeias (2012).

Tal processo de emancipação é fundamental para compreendermos o funcionamento das personagens (por ora, ainda vamos chamá-las assim) dos exemplos que iremos apresentar. Neles, as personagens não são representações de um indivíduo ou tipo (cf. BONFITTO, 2017, p. 96) nem são tomadasapenas como "vetores [ou espelhos] do imaginário, mas [...] [são] produtor[a]s de formas e imagens entre outras formas e outras imagens", tornando-se operadoras e reveladoras "privilegiad[as] das tensões entre realidade e teatralidade, figuração e imaginário". (RYNGAERT; SERMON, 2006, p. 110 - tradução nossa).

Em acordo com uma abordagem histórica das formas artísticas, os pesquisadores Jean-Pierre Ryngaert e Julie Sermon (2006, p. 83 - tradução nossa) defendem que "os modos de definição [da] personagem são uma espécie de teste sensível da época a que pertencem". No que diz respeito ao período mais recente da história ocidental, no exame da produção dramatúrgica realizada nas últimas décadas, os autores compreendem que muitas das personagens com que temos nos deparado na literatura dramatúrgica e nos palcos correspondem a identidades já mais assumidamente distantes do ideal unitário comentado por Candeias (2012). Correspondem, agora, no sentido em que os autores colocam, à concepção de identidade desenvolvida na modernidade tardia e entendida por Stuart Hall (2015, p. 11-2) como "formada e transformada continuamente em relação às formas pelas quais somos representados ou interpelados nos sistemas culturais que nos rodeiam".

Segundo o sociólogo, o deslocamento/descentração do sujeito cartesiano de seu lugar no mundo social e cultural e de si mesmo, a perda de um "sentido de si" (HALL, 2015, p. 10) estável é decorrente de "uma série de rupturas nos discursos do conhecimento moderno". Em sua análise, Ryngaert e Sermon percebem o afastamento da personagem moderna e contemporânea do antigo ideal de unidade como igualmente decorrente das rupturas descritas por Hall: embora não se refiram explicitamente ao sociólogo, citam a psicanálise, a filosofia da linguagem e a crítica marxista para fundamentar a sua argumentação. Visão que segue em diálogo também com Candeias (2012, p. 70), na medida em que a autora afirma que "a partir da vigência dessas teorias científicas, a preferência dos dramaturgos[/as] por figuras multifacetadas é significativa". Para Ryngaert e Sermon (2006, p. 84) seria, então, com esse contexto epistemológico habitando o imaginário dos dramaturgos e dramaturgas que uma boa parte do teatro dos últimos sessenta anos vem sendo escrita. Dizemos "boa parte" porque, conforme Candeias (2012, p. 70) alerta, "não é possível adotar essas afirmações de modo absoluto, uma vez que as dramaturgias contemporâneas não apresentam exclusivamente esse tipo de figura", objeto de nosso interesse.

\section{Da necessidade de renovação lexical}

Se novos fenômenos pedem novas formas de designação, entre a crítica francesa "Figura" (assim grafada por Deleuze (1981)) vem sendo utilizado para designar o que já não pode mais ser lido como personagem stricto sensu e que tampouco, cremos, se encaixa nos limites da "impersonagem", 
nos termos de Jean-Pierre Sarrazac (2017) ${ }^{1}$. De acordo com a pesquisadora Cristina Dantas (2010, p. 73), é pelo menos desde os anos 1920, com o Expressionismo, que o termo passa a ser utilizado em virtude do "desconforto dos diretores e atores de usarem [...] 'personagem"” para se referir às peças daquela escola estética. Segundo a pesquisadora, já naquele período "Manifestava-se a opinião [de] que o ator no palco - em certos papéis - não era mais personagem" e, embora ainda não se soubesse dizer bem o que ele era, o uso de "figura" (grafada no diminutivo por Dantas), "na sua natureza indeterminável", resolvia provisoriamente o problema.

Mas a questão da renovação lexical demandada por uma série de dramaturgias escritas a partir de então é seriamente considerada pela crítica e, por volta da segunda metade do século XX, o termo, antes provisório, passa a ser utilizado justificadamente para se referir aos seres ficcionais que "escapam da influência da palavra 'personagem' ao questionarem seus pressupostos [aristotélico-hegelianos] ou frustrá-los". (RYNGAERT; SERMON, 2006, p. 10 - tradução nossa).

"Figura", conforme utilizada por Ryngaert e Sermon em suas análises, toma como base a noção homônima lançada por Jean-François Lyotard (1979) e desenvolvida depois por Gilles Deleuze (1981). Em Lyotard, ela aparece pela primeira vez no livro Discurso, Figura, escrito na sequência das revoluções que marcaram a França de 1968, e se

\footnotetext{
1 Os exemplos que o autor traz em Poética do drama moderno para desenvolver a sua noção de impersonagem, embora apresentem fatores de fragmentação da personagem da tradição aristotélico-hegeliana, não chegam, como o autor afirma, a romper "definitivamente" com "o quadro tradicional da mimese". Isso na medida em que as potenciais fraturas naquele modelo encontram-se justificadas dramaticamente, no interior da própria fábula, mantendo as personagens no regime figurativo. Em nossa pesquisa, além de impersonagem, evitamos também o uso da acepção demasiadamente vaga de "ser ficcional" e da eminentemente técnica "actante-texto", proposta por Matteo Bonfitto $(2017 ; 2006)$ com referência nos estudos da Semiótica. Optamos, enfim, por utilizar Figura, cuja base teórica discutiremos resumidamente na sequência, acreditando que ela fornece potentes estratégias de compreensão e análise de dramaturgias modernas e contemporâneas.
}

insere numa proposição de "desconstrução ou de alteração da organização formal das coisas" (LYOTARD, 1979, p. 18 - tradução nossa), para o quê, segundo Lyotard, fazia-se necessário abandonar o paradigma dialético hegeliano e assumir "uma certa imitação do artista [...] no comportamento político radical". (1979, p. 18 - tradução nossa).

Como parte da criticada "organização formal das coisas", o discurso logocêntrico é igualmente atacado: a discussão apresentada pelo filósofo vem, justamente, a posteriori da

\begin{abstract}
complexa e dificultosa - e, sem dúvida, discutível - tarefa de desmonte logocêntrico através da reivindicação da figura contra o discurso linear e [...] [da defesa de uma] linguagem que superaria a significação da coisa para estabelecer ou reafirmar uma relação de designação ou fio direto com a coisa referida. (LYOTARD, 1979, p. 24 - tradução nossa; grifos do autor).
\end{abstract}

Embora a questão do figural lyotardiano vá além da problemática da preferência do discurso versus o desprezo ao logos - postura, à época, "quase normativa" - esse é, talvez, o principal ponto de interesse de Deleuze no desenvolvimento que opera a partir da análise da pintura de Francis Bacon. Se, para Lyotard, os "homens de linguagem" fecham na clausura do discurso "tudo aquilo que implique sentido" (1979, p. 31 - tradução nossa), a diferença que a arte e, nela, a figura provocariam ao refutar o discurso de dentro, conforme a posição que lhes cabe (1979, p. 32), é que, mesmo enquanto linguagem, não apresentariam uma significação. A figura é, assim, ela mesma, uma forma de discurso que transcende o símbolo (1979, p. 22).

Em Deleuze, esse pensamento é traduzido na forma de uma oposição do figural ao figurativo. Seu interesse sobre a pintura de Bacon e a leitura que faz dela em Francis Bacon: lógica da sensação vêm ao encontro de sua filosofia da diferença 
e da crítica à (um tipo de pensamento associado ao logocentrismo e designado por) representação, entendida pelo filósofo como a "reprodução de modelos que subordinam a diferença à identidade", que buscam "reduzir todo tipo de diferença a [...] padrões universais". (MARTINS, 2010, p. 42).

Para Ryngaert e Semon, a seu turno, Figura/ figural surge como uma alternativa à noção de pós-dramático de Lehmann para pensar as dramaturgias que "envolvem um processo de figuração que não é mais figurativo (ilustrativo, narrativo), mas performativo (poético, rítmico)". (RYNGAERT; SERMON, 2006, p. 162 - tradução nossa). Tal proposição alternativa se dá em consideração ao fato de que a crise que reconhecemos na forma dramática não implica necessariamente a ausência de ficção que a valorização do tempo-espaço objetivos do acontecimento cênico presente na leitura lehmanniana sugere. Ao contrário, segundo a compreensão desses críticos franceses, a fala continua a convocar situações e presenças imaginárias e as dramaturgas/os ainda "contam histórias, ficcionalizam situações, inventam comunidades imaginárias". (2006, p. 113 - tradução nossa).

De nossa parte, enxergamos muitas aproximações entre os aspectos da obra de Bacon que Deleuze levanta e analisa para a construção de sua própria compreensão de Figura e as (aqui chamadas) Figuras presentes nas dramaturgias modernas e contemporâneas cuja análise e crítica temos acompanhado em nossas pesquisas. Doravante, tomamos esses aspectos como categorias de análise para um recorte dessas dramaturgias, conforme discussão que segue abaixo.

\section{Isolamento}

O primeiro aspecto, que temos tomado como a pedra de toque no estudo dos textos dramatúrgicos escritos a partir da virada do século $X I X / X X$, é o isolamento. $\mathrm{Na}$ introdução ao Léxico do drama moderno e contemporâneo, Sarrazac apresenta essa questão com muita clareza: para o autor, "essa crise [do drama, nos termos de Peter Szondi (2011)], que irrompe nos anos 1880, é uma resposta às novas relações que o homem mantém com o mundo e a sociedade. [...] novas relações [que] instalam-se sob o signo da separação [que tomamos aqui como análogo ao do isolamento]". (2012, p. 23 - grifo do autor).

\begin{abstract}
$O$ homem do século $X X-O$ homem psicológico, o homem econômico, moral, metafísico, etc. - é sem dúvida um homem "massificado", mas é sobretudo um homem "separado". Separado dos outros (em virtude, frequentemente, de uma promiscuidade excessiva), separado do corpo social, que não obstante, agarra-o como a uma tenaz, separado de Deus e das forças simbólicas, separado de si mesmo, dividido, fragmentado, despedaçado. (SARRAZAC, 2012, p. 23).
\end{abstract}

Segundo a lógica dialética(-hegeliana) da leitura de Szondi (2011), que Sarrazac retoma, essa separação encontrou formalização dramatúrgica na separação mesma entre o sujeito/subjetivo/lírico e o objeto/objetivo/épico, cuja síntese constitui o princípio da forma dramática. Dessa ruptura é que decorre a fragmentação e crise de todos os elementos centrais àquele modelo, como o diálogo, a fábula, o conflito e a personagem. A título de exemplo, podemos citar a subjetivação do conflito observada no drama burguês (também conforme teorização de Szondi (2004)): em peças como O Mercador de Londres, do dramaturgo inglês Georg Lillo, no lugar da inter-ação o que encontramos é um conflito subjetivado, internalizado às personagens, impelindo o drama a evidenciar os traços líricos e épicos que Ihes são parte. Como uma espécie de "efeito colateral", tal subjetivação se converte em fator de fragmentação e isolamento das personagens.

Séculos depois e já em outro contexto cultural, essa "força de isolamento", como vai chamar Deleuze (1981, p. 43), seguirá atuando e se reve- 
lando em dramaturgias como as de Grace Passô. Em Marcha para Zenturo (2010), por exemplo, a autora refina dramaturgicamente um jogo surgido durante as improvisações para a criação do espetáculo, no qual "as reações [das personagens] sofriam um estranho retardo, nas falas e nos gestos". (PASSÔ, 2012, p. 09). Tal qual num Tchekhov futurista, as personagens tecem ali, de forma muito particular, um "diálogo de surdos": a resposta para uma pergunta feita só chega ao seu interlocutor depois que o espaço entre uma fala e outra já foi preenchido por novas perguntas e respostas, também a descompasso, de modo que o que se ouve são, quando muito, ecos de uma fala já passada. Assim, ninguém está, nunca, presentificado a ninguém e todos estão isolados em seu próprio tempo.

Em Francis Bacon: a lógica da sensação, Deleuze observa o recorrente procedimento de isolamento das Figuras no contexto da composição pictórica dos quadros do pintor anglo-irlandês, isolamento realizado, segundo o próprio Bacon, conforme citação de Deleuze (1981, p. 2 - grifos do autor), "para conjurar o caráter figurativo, ilustrativo, narrativo, que a Figura teria necessariamente se não estivesse isolada".

Em havendo duas figuras, observa o filósofo, há necessariamente uma história insinuada ou que tende a se insinuar. Elas são isoladas, então, no sentido da composição de relações não narrativas entre si. Mas são isoladas, também, de um ambiente inteligível - o mais próximo que encontramos disso sendo uma cadeira, cama ou pia onde, em alguns casos, a "figura" se encontra apoiada. No mais, o que temos é o seu isolamento visualmente denotado ou reforçado pela presença de formas geométricas que a circundam e, completando a composição, "grandes chapados de cor viva, uniforme e imóvel" (DELEUZE, 1981, p. 3), que não guardam relação de profundidade ou distanciamento com a "figura", mas estão ao seu lado, no mesmo plano que ela. De acordo com Deleuze (1981, p. 17), são esses os três elementos de base presentes nos quadros de Bacon: Figura, contorno e estrutura (o chapado).

Figura 1 - Três estudos de Lucian Freud (1969), de Francis Bacon.

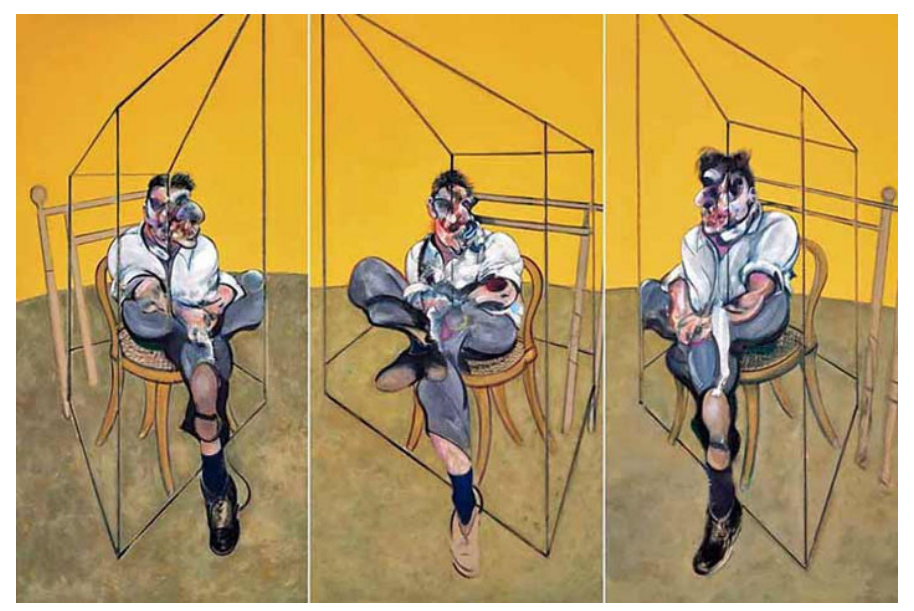

Fonte: https://bit.ly/2L2sB5w.

O contorno - que, no tríptico acima, aparece como uma espécie de cubo no qual a Figura está inserida -, Deleuze o entende como sendo uma membrana que "assegura a comunicação nos dois sentidos [dentro-fora; fora-dentro]" (1981, p. 17) entre os demais elementos da composição. Ao invés da interação entre figuras diversas, o que o filósofo percebe nesses quadros é o movimento de uma única Figura em relação ao chapado e vice-versa, o que é, ao fim e ao cabo, um movimento da Figura sobre si mesma. Assim, segundo o filósofo, o isolamento não limita

[...] a Figura à imobilidade; pelo contrário, [...] [torna] sensível uma espécie de encaminhamento, de exploração da Figura em seu lugar, ou sobre si mesma. É um campo operacional. A relação da Figura com seu lugar isolante define um fato [uma situação em lugar de uma ação, como diríamos no âmbito das dramaturgias modernas e contemporâneas] [...] E a Figura, assim isolada, torna-se uma Imagem, um Ícone. (DELEUZE, 1981, p. 1). 
Ainda nesse sentido, Deleuze (1981, p. 7) observa como "a Figura [...] sentada numa cadeira [...] às vezes [...] parece mesmo à espera do que vai se passar. Mas o que se passa, ou vai passar, ou já está passando [ou já se passou, acrescentamos], não é um espetáculo, uma representação". No ensaio "Sete observações sobre a possibilidade de um trágico moderno - que poderia ser um trágico (do) quotidiano", Sarrazac (2013) chama atenção para o fato de que, nas dramaturgias modernas e contemporâneas, há uma frequência de peças que iniciam suas narrativas num momento posterior à catástrofe que, no modelo aristotélico-hegeliano, seria o cume do enredo. Em decorrência dessa mutação na forma dramática, as personagens, antes ativas (persona (máscara) + agem (ação)), teriam se tornado reflexivas (cf. SARRAZAC, 2017, p. 175), o presente dramático funcionando apenas como um pretexto para a evocação e ruminação do passado.

A espera é, aliás, desde Tchekhov, e de maneira emblemática em Samuel Beckett, um dos grandes temas da dramaturgia europeia do século XX. Não por este motivo, mas por outro que o tangencia, Deleuze também aponta uma semelhança entre os trabalhos de Bacon e Beckett: o movimento de translação de suas Figuras.

Oriundo de uma espécie de recorte de um movimento que a Figura poderia fazer, essa translação é o já indicado movimento da Figura sobre si mesma (nesse sentido, um movimento também de rotação). Lembramos da Winnie de Dias Felizes (1961), de Nagg e Nell de Fim de partida (1957) e de Didi e Gogô em Esperando Godot (1952), claro. Mas é devido às figuras presentes em Quad (1981) que podemos dizer, com Deleuze (1981, p. 22), que nunca "Beckett e Bacon estiveram tão próximos, por um pequeno passeio ao modo dos personagens de Beckett, que também se deslocam aos trancos sem sair do círculo ou do paralelepípedo".
Figuras 2 e 3 - Homem carregando uma criança (1956), de Francis Bacon e Cena de Quad II (1981), tela-peça de Samuel Beckett dirigida pelo próprio dramaturgo.
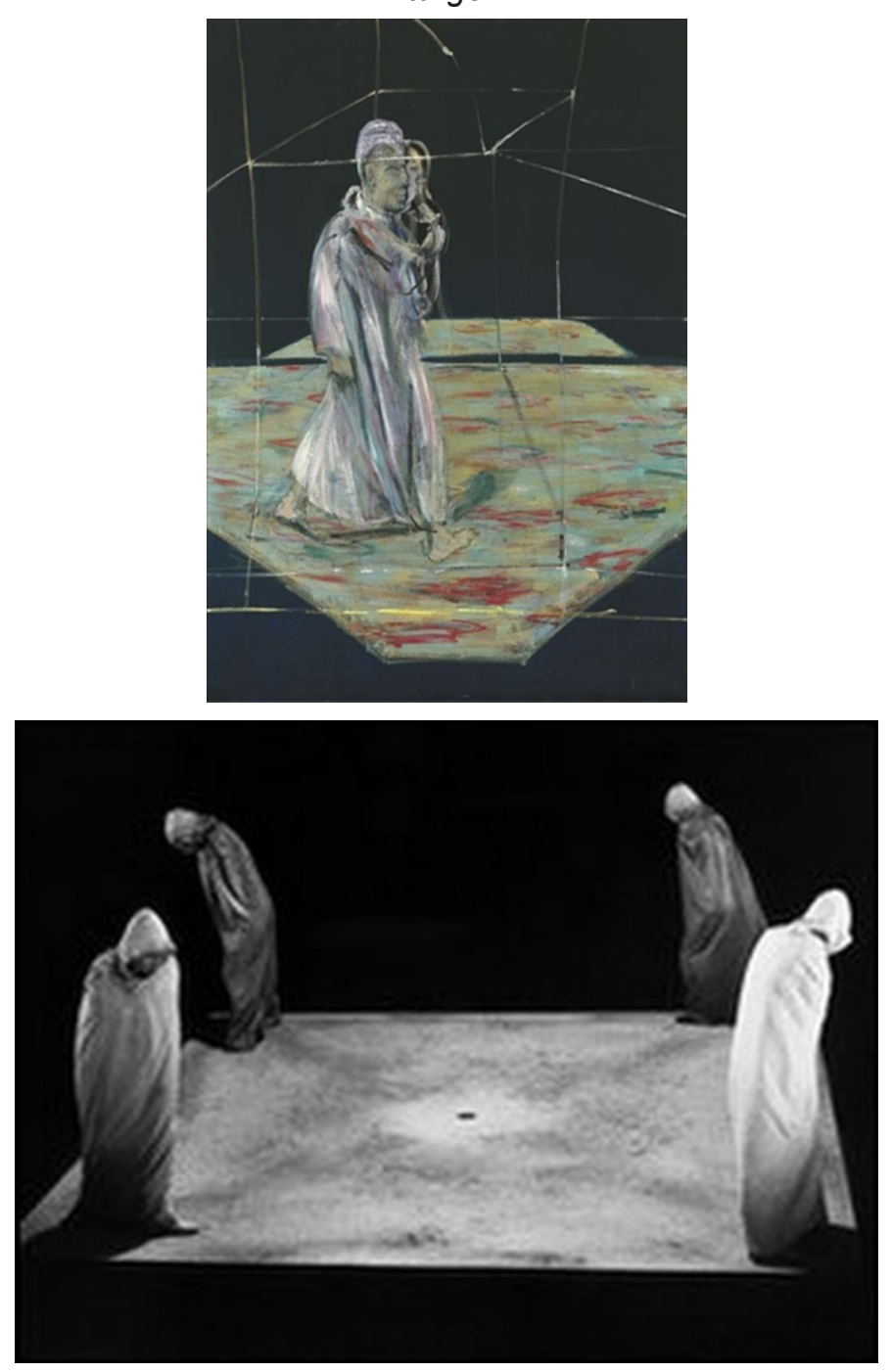

Fontes: https://bit.ly/2ZkDFQA e https://bit.ly/2ZoMoFu, respectivamente.

Divididas em Quad I e II, essas tele-peças apresentam em sua dramaturgia a repetição de sons e do que podemos entender como uma coreografia executada pelos, assim chamados no texto, "jogadores" ("players"). Sem se comunicarem verbalmente, essas Figuras giram em torno do tablado e em direção ao seu centro, no qual se encontra um quadrado menor, delimitado apenas pela luz - uma "zona de perigo" que o autor chama de "E" e a qual as 
Figuras evitam, assim como evitam o contato umas com as outras, criando um padrão de tensão interna.

Longe de apelar para a racionalidade do espectador, tanto o quadro de Bacon quanto a tele-peça de Beckett obedeceriam ao que Cézanne chamou de uma "lógica da sensação" - donde o título do livro de Deleuze que trazemos a debate -, lógica distinta da racionalidade logocêntrica a cuja crítica o livro de Lyotard que comentamos antes segue. Nesses casos, a forma estética proposta remeteria não a significações, mas a sensações; não a um objeto que buscaria representar (como no regime figurativo), mas agindo "imediatamente sobre o sistema nervoso, que é a própria carne”. (DELEUZE, 1981, p. 19).

Os movimentos repetitivos de translação dos quadros, mas poderíamos dizer também das peças evocadas aqui, se explicariam pela "elasticidade da sensação" que atravessa cada obra. Essa seria a chave para a compreensão (sensação? (o verbo, não o substantivo)) de quadros como Três estudos de Lucian Freud (1969), que reproduzimos acima. Como nos outros trípticos do pintor, encontramos diferentes qualidades (níveis) de sensação em cada quadro que o compõe, revelando movimentos internos ao tríptico e à Figura que o habita, não decorrendo dessas transições de qualidades, em princípio, uma narrativa - embora a leitor/a/espectador/a tenha autonomia para produzi-la, se for este o caso.

No limite, diz ainda Deleuze, "é um movimento no mesmo lugar, um espasmo, que testemunha [...] a ação das forças invisíveis sobre os corpos (de onde vem [sic] as deformações do corpo devidas a esta causa mais profunda)". (DELEUZE, 1981, p. 22 - grifos do autor). A Figura como um corpo isolado, mas também como um corpo deformado, conforme se verá adiante.

\section{Deformação}

Figura 4 - Figura no Lavabo (1976), de Francis Bacon.

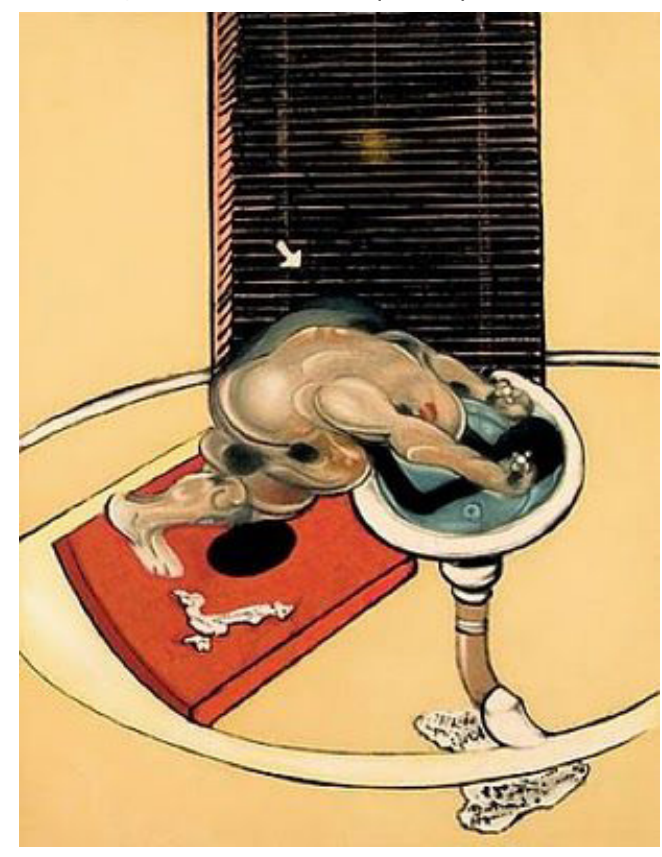

Fonte: https://bit.ly/2HegGQE.

Imagem de abjeção. Neste quadro, o elemento do contorno, a membrana que separa e comunica a Figura ao chapado é o lavabo, que delimita o espaço circularmente. Deleuze observa como a Figura em questão tenta escapar "por um ponto de fuga no contorno para se dissipar na estrutura material" (1981, p. 9) e como, para tanto, ela se alonga, contorce e distorce. Um espasmo a domina e ela "tenta escapar por um de seus órgãos, para reencontrar o chapado, a estrutura material" (DELEUZE, 1981, p.8) e nele se dissipar. Seria essa, segundo Deleuze, a relação necessária com a estrutura material: é o movimento sobre si em função dessa estrutura e na passagem pelos diferentes níveis de sensação que promove a deformação das Figuras e as liberta de sua função narrativa. O próprio Bacon, em entrevista a David Sylvester (apud MARTINS, 2010 , p. 43), fala sobre a questão, comentando que seu "processo pictórico [...] vai da forma à deformação" e que o que ele pretende é "distorcer a coisa até um nível que está muito além da aparência, mas na distorção voltar a um registro da aparência". 
Neste ponto, Deleuze traz Antonin Artaud e sua ideia de um corpo sem órgãos para a discussão, afirmando que "a Figura é precisamente [esse] corpo sem órgãos [...] que se define pela presença temporária e provisória de órgãos determinados". (1981, p. 24-5 - grifos do autor). A ausência de órgãos significa, em Artaud, a ausência da lógica funcional e cartesiana segundo a qual esses órgãos, cada qual com sua função pré-estabelecida, se combinam num organismo.

Em tom de manifesto, o filósofo diz:

"[...] Nada de boca. Nada de língua. Nada de dentes. Nada de laringe. Nem exôfago [sic]. Nem estômago. Nem ventre. Nem ânus". Toda uma vida não orgânica, pois o organismo não é a vida, e a aprisiona. O corpo é inteiramente vivo, e portanto não orgânico. Assim a sensação, quando atinge o corpo através do organismo, toma um movimento excessivo e espasmódico, rompe os limites da atividade orgânica. (DELEUZE, 1981, p. 24).

Apesar da nomenclatura contrariante, essa noção artaudiana encontra eco noutra lançada por Valère Novarina. Em Carta aos atores, o dramaturgo apresenta a ideia de um corpo com órgãos como sendo o corpo interior de ambos atrizes e atores, mas associando esse interior ao feminino, a um modus operandi ligado à anatomia feminina. Nesse sentido, traz a imagem de um corpo (in)vaginado, esburacado:

Todos os grandes atores são mulheres. Pela consciência aguda que têm de seu corpo de dentro. Porque sabem que seu sexo está dentro. Os atores são corpos fortemente vaginados, vaginam com força, representam com o útero; com a vagina, não com o pau. Representam com todos os buracos, com todo o interior do corpo esburacado, não com seu troço teso.
Não falam com a ponta dos lábios, toda sua fala Ihes sai pelo buraco do corpo. Todos os atores sabem disso. E querem impedi-los disso. De serem muIheres e de vaginarem. Querem que indiquem, mostrem uma coisa depois da outra, fálus com sentido, membros másculos tesos que designam, flechas bem adestradas que apontam 0 sentido, indicadores e executores. (NOVARINA, 2005, p. 24).

Enxergamos nessa reflexão de Novarina as metáforas para dois modos de atuação cênica distintos. O corpo que o ensaísta designa como "fálico" seria aquele ligado às convenções dos teatros e das dramaturgias logocentrados, pautados pelo primado da racionalidade (avessa, nesse sentido, à sensação cezanneana) e nos quais são definidos sentidos prévios ao momento de seu acontecimento com/diante do público/leitor/a; é o organismo cartesiano que Artaud rejeita.

Já o corpo a que Novarina chama de "vaginado" seria este - assim o entendemos - apto a lidar com uma série de dramaturgias produzidas a partir das vanguardas históricas ou mesmo apto a trazer outros sentidos e possibilidades a textos clássicos, como fizeram tantos encenadores notadamente a partir da segunda metade do século XX ("ver o velho texto todo queimado, todo destruído pela dança do ator levando todo seu corpo dentro dele" (Novarina, 2005, p. 13)), a condição para isso sendo "esburacar-se"; noutros termos, permitir que os sentidos se façam e o atravessem na performance (i.e., na ação) mesma desses textos, conforme eles irão reverberar no corpo de cada atriz ou ator com quem entrar em contato.

Sobre isso, vejamos um comentário que o dramaturgo fez sobre duas das personagens de sua primeira peça, O ateliê voador (1974). Apesar de conservar elementos-chave do modelo dramático, como a intriga e a forma dialogada, a leitura que o próprio autor faz das personagens Senhor Bou- 
cot e Senhora Boca (em tradução de Angela Leite Lopes) nos remete às Figuras baconeanas. Diz ele:

Boucot tem escapamentos por toda parte, quer tapar tudo com a boca). Seu medo enorme do ânus ("O que é isso?"), porque é por ali que tudo escapa. Boucot sem ânus, Boucot buraco sem fundo, apertando continuamente seu esfíncter bucal, consoando duramente, articulando, atacando com a boca musculosa; [...] Partitura de Madame Boucot. Ela nunca foi pensada como "personagem", mas como algo que viesse mascarar, fissurar, furar, tal qual [...] uma síncope, uma expiração, um excesso. (NOVARINA, 2005, p. 11 e 14).

Os buracos, nós podemos percebê-los na Figura no lavabo (1976) reproduzida acima: eles aparecem tanto na espécie de piso que se vê colado à pia-contorno quanto em alguns pontos no corpo mesmo da Figura. Mas há os quadros em que o buraco é a própria boca da Figura, tendo a mesma função de escape que Novarina atribui a do Senhor Boucot, o que também será objeto de observação de Deleuze. Notadamente em Papa Inocêncio $X$ (1953), o filósofo pensa ser o grito, ali percebido, a operação pela qual o corpo se escapa pela boca.
Figura 5 - Papa Inocêncio X (1953), de Francis Bacon.

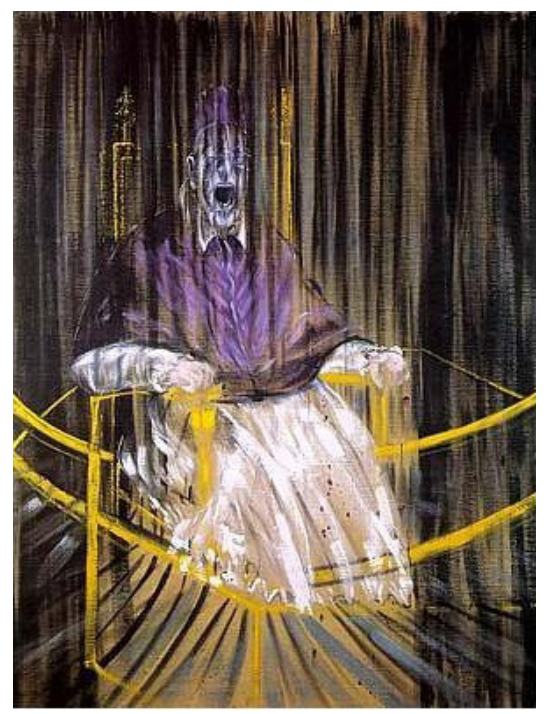

Mas escapa de quê?

Fonte: https://bit.ly/2zdCrff

Dissipação

Por fim, a respeito das Forças atuantes sobre a pintura de Bacon, e comentando ainda as dinâmicas operadas entre a Figura, o contorno e o chapado, Deleuze observa como um dos efeitos provocados por essas dinâmicas é o do desaparecimento da Figura ou a sua dissipação no próprio chapado em relação ao qual se movimenta. Nesses casos,

O chapado se [abre] como um céu vertical ao mesmo tempo que se [encarrega] de mais a mais de funções estruturantes: os elementos de contorno determinarão de mais a mais as divisões, as seções planas e as regiões no espaço que forma a moldura livre. Mas ao mesmo tempo a zona de borramento ou de limpeza, que faz surgir a Figura, vai agora valer por si mesmo [sic], independentemente de toda forma definida, aparecer como pura Força sem objeto [...]. (DELEUZE, 1981, p. 16). 
A título de exemplo, podemos citar o quadro Paisagem, de 1978:

Figura 6 - Paisagem (1978), de Francis Bacon.

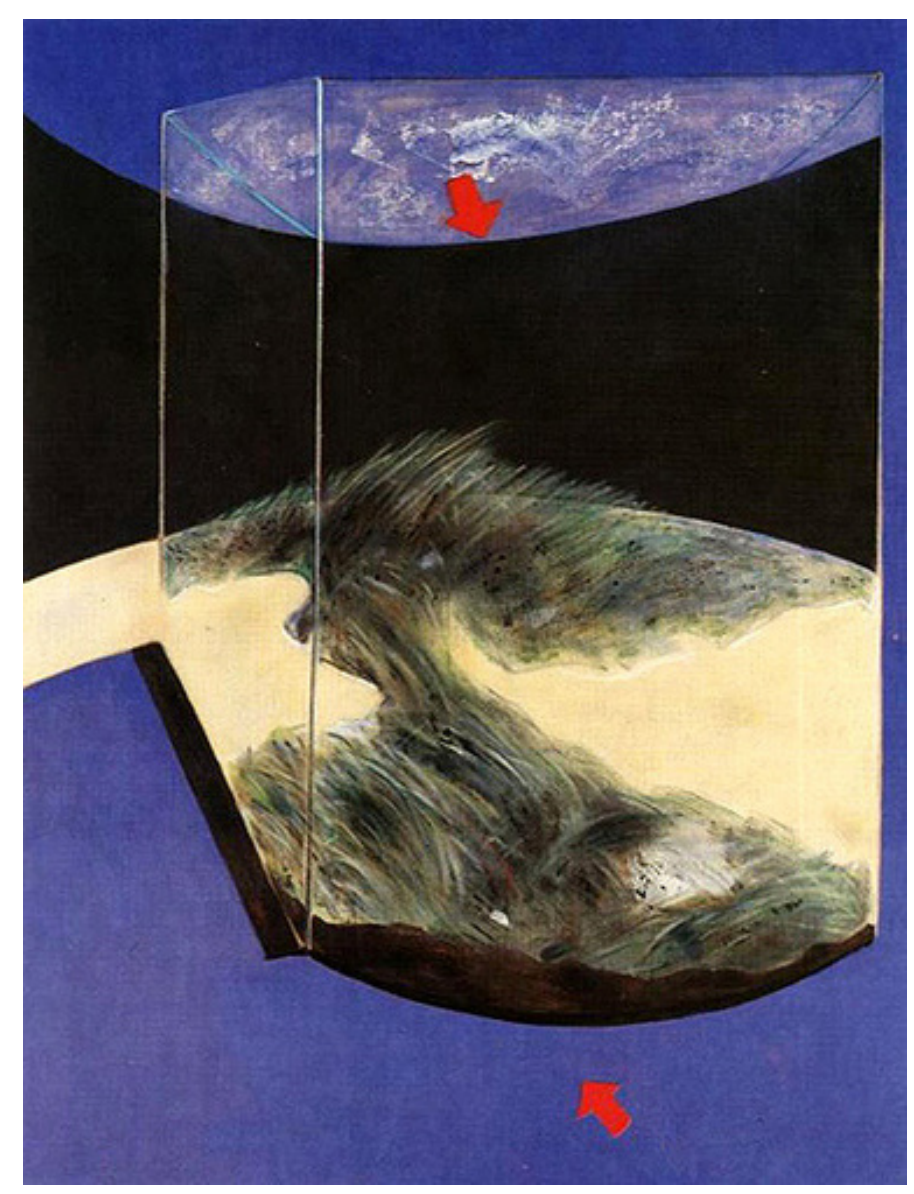

Fonte: https://bit.ly/2zcfjxv

Enquanto o contorno, semelhante ao do tríptico de Três estudos de Lucian Freud, permanece inalterado, o chapado se abre conforme a descrição de Deleuze, como um céu vertical, cujas partes o contorno-cubo passa a interligar. Já em lugar da Figura, temos a presença de uma área marcada por "traços assignificantes destituídos de função ilustrativa ou narrativa" (DELEUZE, 1981, p. 3 - grifos do autor), valendo, segundo o filósofo, por si mesma.

A ausência de Figuras e a consequente proeminência do chapado e do contorno, que, segundo Deleuze, assumem funções estruturantes, nos remetem a uma experiência anacrônica - no sentido de que radicalidade semelhante só pode ser vista de novo cerca de dois séculos depois - realizada pelo arquiteto, cenógrafo e pintor Jean-Nicolas Servan (Servandoni), quem, na mesma França do período neoclássico, criou espetáculos nos quais "nenhuma ação humana ocorria efetivamente [...] [e nos quais] as 'personagens' [pintadas no dispositivo cenográfico] funcionavam [apenas] como referência para a apreensão da proporção espacial proposta pelas imagens". (TUDELLA, 2013, p. 401). A ausência de atrizes/atores se justificava pela escolha poética do artista em elevar o discurso visual a primeiro (e, até onde fosse possível, exclusivo) plano, fundamentando a espetacularidade da cena na ação da luz.

Tudella comenta ainda que os seus espetáculos buscavam a "emoção [...] através da apresentação sucessiva de espaços tratados de modo próprio, pela luz". (TUDELLA, 2013, p. 399). Poderíamos pensar que ele já atuava, ali, segundo a lógica da sensação de que Cézanne fala e que Deleuze retoma. No entanto, apesar de desconsiderar "a narrativa linear da representação teatral da época" e de deslocar a função do cenário de mero acessório para protagonista da cena (no diálogo com a iluminação), ele ainda buscava a representação figurativa da realidade, ao empregar um "alto grau de excelência na ilusão de profundidade". (TUDELLA, 2013, p. 399). Donde a necessidade de pintar figuras humanas em seus cenários, para, como dissemos, referenciar a proporção dos mesmos.

Mas o procedimento baconeano de dissipação também nos remete a experiências de escrita que, indo além do laconismo presente em tantas das dramaturgias do pós-II Guerra, se apresentam basicamente na forma de uma grande didascália. Pensamos, por exemplo, na peça Descrição de uma imagem (1984), de Heiner Müller. Escrita a partir do desenho que uma estudante de cenografia fez de um sonho que tivera, o texto apresenta uma voz narrativa não identificada e descreve o referido desenho, acrescentando a essa descrição, intertextualmente, referências a outras obras. No entanto, também este artista não se furta a introduzir uma 
figura humana. Logo no início da descrição, lemos:

uma mulher que domina a metade direita da imagem, sua cabeça divide montanhas, o rosto é suave, muito jovem, o nariz longo demais, um inchaço na base, talvez de um soco, o olhar no chão, como se não pudesse esquecer uma imagem e ou não quisesse ver outra, o cabelo comprido de mechas, loiro ou cinza esbranquiçado, a luz dura não diferencia, a roupa um casaco de pele [...]. (MÜLLER, s/d, p. 1).

Essa descrição segue, ainda, nas linhas subsequentes - mas segue como que dissipada entre os demais elementos que compõem a imagem, não tendo função narrativa.

Voltando mais uma vez a Beckett, podemos identificar esse movimento de dissipação da Figura na cena da já citada Winnie de Dias Felizes, que do primeiro para o segundo ato da peça vê seu corpo ainda mais soterrado no monte indicado na rubrica - correspondente aos contornos de Bacon, segundo nossa interpretação -, a tendência sendo desaparecer de todo, num terceiro ato imanente.

Um último exemplo que gostaríamos de trazer, ainda no que se refere à Força de dissipação, é o espetáculo PROJETO bRASIL, da companhia brasileira de teatro. Na rubrica inicial, lemos:

preto sobre preto espaço que sugere movimento parede curva, sobrepalco circular que gira, sentido espiral fim de festa (ABREU, 2016, p. 53).

$\mathrm{Na}$ proposta da encenação, criada conjuntamente com a dramaturgia e o texto (cf. ABREU, 2016, p. 51), o monocromatismo negro abrange todos os elementos visuais da cena e só é quebrado por um vermelho que surge no discurso 11. Noutra cena, o preto aparece, também, numa tinta que é jogada contra as atrizes/atores e o fundo, ele mes- mo já preto. Essa imagem será levada a um átimo ao final do espetáculo, quando, quase sucumbidos à exaustão, as quatro atrizes e atores ("4 pessoas. 4 bichos. eles estão ali. eles se movem. os bichos se movem sutilmente. 3 bebês. 1 mulher e 3 bebês. [...] imagens difusas" (ABREU, 2016, p. 79) se deixam largar encostados na parede curva, sentados sobre o chão. No que podemos ver, talvez, uma imagem de dissipação das Figuras - embora, aqui, não isoladas - na estrutura, como sugere Deleuze.

Ou, para ficarmos apenas com a rubrica citada acima, será que não podemos dizer que a cor chapada ("preto sobre preto"), a parede curva (a estrutura), o movimento e o sobrepalco circular (o contorno), tal como colocados, lembram uma descrição de um quadro de Bacon? Essa impressão é corroborada por um comentário que Danielle Ávila Small tece em crítica ao espetáculo. Sobre a cenografia de Fernando Marés, ela diz:

É um preto aberto, declarado. Vemos o chão e as paredes. Não há uma dinâmica de separação entre figura e fundo na relação entre os atores e o cenário. O movimento autônomo do dispositivo cenográfico emancipa o fundo, torna-o independente, causador mais que ferramenta. (SMALL, 2015, s/p).

\section{Considerações finais}

Através desses exemplos, trazidos na tentativa de investigar a pertinência da concepção de Figura (bem como das Forças atuantes sobre ela) elaborada por Deleuze para a análise de algumas dramaturgias modernas e contemporâneas, pudemos considerar que a tendência ao desaparecimento da figura humana de ambas literatura dramatúrgica e cena, tendência disparada inicialmente pelo isolamento dessa figura, não conseguiu se efetivar (ainda - conseguirá um dia?) mesmo nas dramaturgias mais contestadoras da tradição aristotélico-hegelia- 
na, desde os simbolistas até as escritas de autores como Müller, Beckett e Abreu, e mesmo antes, em experiências isoladas como a de Servandoni. O que não quer dizer que a presença da figura humana, notadamente dentro do (no âmbito desta pesquisa) chamado regime figural, não possa ser e não venha sendo problematizada, tanto no texto quanto na cena.

Em todo caso, como observam Ryngaert e Sermon, a introdução do termo Figura nos discursos acerca da dramaturgia/teatro tem provocado deslocamentos consideráveis na nossa compreensão sobre os seres ficcionais na cena: enquanto que a personagem (leia-se, a aristotélico-hegeliana) é entendida como uma entidade substancial, pré-existente à representação, ao acontecimento cênico, parecendo a leitor/a/espectador/a "existir não apenas no interior, mas fora da narrativa dramática que lhes dá vida" (FUCHS, 1996, p. 24 - tradução nossa), a Figura é tomada sob uma aparência que até pode adquirir alguma substância no decorrer da cena², mas que existe apenas nela e cujo aspecto mais interessante é, antes, a forma como aparece em cena e na relação com os demais elementos que a compõem.

Como desdobramento da análise diacrônica que fizemos do processo de mutação da personagem dramática até as suas configurações mais recentes, entre elas as aqui denominadas de Figuras, interessou-nos, em nossa pesquisa, pensar as consequências que esse processo de mutação provocou no trabalho das atrizes e atores, cuja base, em muitos casos ainda de tradição eminentemente dramática, se mostra insuficiente para a lide com essas dramaturgias. Noutra oportunidade, priorizaremos a discussão sobre esse desdobramento. Por ora, esperamos ampliar o pensamento analítico sobre as Figuras que habitam as dramaturgias modernas e contemporâneas através dos aspectos e elementos emprestados dos estudos de Lyotard

2 Segundo Ryngaert e Sermon (2006, p. 11 - tradução nossa), "A figura coloca a questão da personagem como forma de aparência antes de considerá-la como uma entidade substancial. Faz dela uma questão de figuração e não um objeto hermenêutico". e Deleuze para os estudos de nossa própria seara.

\section{Referências}

ABREU, Márcio. MARÉ/PROJETO bRASIL. $1^{\text {a }}$ ed. Rio de Janeiro: Cobogó, 2016.

BONFITTO, Matteo. O ator compositor. São Paulo: Perspectiva, 2006.

O ator pós-dramático: um catalisador de aporias? In: GUINSBURG, Jacó; FERNANDES, Silvia (orgs.). O pós-dramático: um conceito operativo? São Paulo: Perspectiva, p. 87-100, 2017.

CANDEIAS, Maria Lúcia Levy. A fragmentação da personagem. São Paulo: Perspectiva, 2012.

DANTAS, Cristina Leite. Outro Kaspar: a língua como recurso ao ator para a elaboração de um ser ficcional no palco a partir de peças-faladas (Sprechstücke) de Peter Handke. Tese (doutorado). 285 f. Universidade Federal da Bahia, 2010.

DELEUZE, Gilles. Francis bacon: lógica da sensação. Tradução não revisada de Silvio Ferraz e Annita Costa Malufe. 1981. Disponível em: http://conexoesclinicas.com.br/wp-content/uploads/2015/12/ deleuze-francis-bacon-logica-da-sensacao-1.pdf. Acesso em: 12 jan. 2019. (No original: Francis Bacon: logique de la sensation. Paris: Aux édittions de la différence, 1981).

FUCHS, Elinor. The death of character: perspectives on theater after modernism. Bloomington: Indiana University Press, 1996.

HALL, Stuart. A identidade cultural na pós-modernidade. Rio de Janeiro: Lamparina, 2015.

LYOTARD, Jean François. Discurso, Figura. BarceIona: Editorial Gustavo, Gilli, 1979.

MARTINS, India Mara. Do figurativo ao figural: uma reflexão sobre a figura em Francis Bacon e Ryan. Revista Eco-Pós, v. 13, n. 2, p. 37-58, 2010.

MÜLLER, Heiner. Descrição de uma imagem. Versão não publicada. S/d. 
NOVARINA, Valère. Carta aos Atores e Para Louis de Funès. Rio de Janeiro: 7Letras, 2005.

PASSÔ, Grace. Marcha para Zenturo. Rio de Janeiro: Cobogó, 2012.

RYNGAERT, Jean-Pierre; SERMON, Julie. Le personnage théâtral contemporain: décomposition, recomposition. Montreuil: Éditions Theatrales, 2006.

SARRAZAC, Jean-Pierre. Léxico do drama moderno e contemporâneo. São Paulo: Cosac \& Naify, 2012.

Sete observações sobre a possibilidade de um trágico moderno - que poderia ser um trágico (do) quotidiano. Pitágoras 500: Revista de Estudos Teatrais do Departamento de Artes Cênicas da Unicamp. Campinas, v. 4, p. 3-15, 2013.

. Poética do drama moderno. São Paulo: Perspectiva, 2017.

SMALL, Danielle Ávila. Exposição e partilha da condição humana. 2015a. Disponível em: http://documentacena.com.br/2015/08/26/exposicao-e-partilha-da-condicao-humana/. Último acesso: 22 de março de 2019.

SZONDI, Peter. Teoria do drama burguês. São Paulo: Cosac \& Naify, 2004.

Teoria do drama moderno. São Paulo: Cosac \& Naify, 2011.

TUDELLA, Eduardo A. S. Práxis cênica como articulação de visualidade: a luz na gênese do espetáculo. Tese (doutorado). UFBA, Salvador, 2013. 629 f.

Recebido: 29/08/2019

Aprovado: $17 / 02 / 2020$ 